

\section{Giriş (Introduction)}

Kablosuz Algılayıcı Ağlar (KAA), kurulu oldukları ortamdaki çevresel verileri gözlemlemek ya da bu ortamı kontrol etmek amacıyla, bulunduğu ortamdan veri toplayan, verileri işlenebileceği bir noktaya işbirliği ile aktaran ve işlem sonuçlarına göre ortamı kontrol eden ağ yapılarıdır (Radhika vd., 2019). İlk olarak, askeri veri toplama ihtiyacından ortaya çıkan KAA'lar, bu alan dışında günümüzde; sağlık, askeri (Madhu vd. 2014), tarım (Rajput vd., 2019) ve endüstriyel (Erdeli vd., 2013) birçok uygulamada etkin bir altyapı desteği sağlamaktadır.

Bir ortam için KAA topolojisi tasarlanırken algılayıcı düğümlerin uygun noktalarda konumlandırılmaları oldukça önemlidir. Tasarlanan topolojinin öncelikle uygulamanın amaçlarını yerine getirirken, veri aktarımı için QoS (Quality of Service) gereksinimlerini sağlaması ve mümkün olduğunca en uzun süre varlığını devam ettirebilmesi beklenmektedir. Ancak, gerçek dünya uygulamalarında, algılayıcı düğümlerin konumlandırılmaları, ortamın fiziki, coğrafi ya da güvenlik risklerinden dolayı istenildiği şekilde gerçekleştirilmeyebilmektedir. Bu durum da, algılayıcı düğ̈̈mlerin algıladıkları verileri merkezi bir düğüme iletmesi sırasında harcanan enerjinin her ağ topolojisinde farklılık göstermesi ile sonuçlanır. Bu noktada en büyük sorun; sınırlı bir pil kaynağı ile etkileştirilen algılayıcı dügümlerin enerji kapasitelerinin sınırlı olmasıdır (Radhika vd., 2019).

Bir KAA ortamındaki algılayıcı düğümlerin yaşam sürelerini arttırmak için düz, hiyerarşik, konum tabanlı ya da QoS gereksinimlerini göz önünde bulunduran yönlendirme protokolleri bulunmaktadır. LEACH, PEGASIS, TEEN, APTEEN ve VGA yönlendirme protokolleri bu protokoller içerisinde hiyerarşik yapıya sahip kümeleme tabanlı olanlarıdır (Radhika vd., 2019). Kümeleme işlemi her bir veri aktarımı çevriminde algılayıcı dügümlerden bazılarının Küme Başı (KB) seçilmesi ve verilerin bu düğümler üzerinden bir Merkezi Düğüme (MD) iletilmesi işlemidir. Ancak, kümeleme tabanlı yönlendirme algoritmalarında algılayıcı düğümlerde harcanan enerjinin verimliliği optimize edilmeden, her bir veri iletimi sırasında rastgele seçilen bir düğümün KB yapılmasıyla veri iletimi gerçekleştirilmektedir. Bunun sonucunda ağdaki veri iletimi sürecinde düğümler gereğinden daha fazla enerji harcamakta ve ağın toplam yaşam süresi kısalmaktadır.

Bu çalışma, kümeleme yaklaşımına dayalı algoritmalardan LEACH (Low-Energy Adaptive Clustering Hierarchy) protokolü üzerine odaklanmıştır. LEACH protokolünde KB seçimi, dügümün coğrafi konumu ve kalan enerjisi dikkate alınmadan rastgele gerçekleștirilir (Asha vd., 2018). Bu durumda, enerjisi bitmek üzere olan algılayıcı dügümlerin, veri iletimi çevrimlerinde $\mathrm{KB}$ seçilerek ömürlerini öngörülen süreden önce bitirmeleri ve kullanılamaz hale gelmeleri ile sonuçlanır. Literatürde, LEACH protokolünü kullanan KAA'larda en uygun KB'leri seçmek ve ağı kümelemek için farklı optimizasyon yöntemleri önerilmiştir; Ahmad vd. (2017) bal arısı algoritmasına dayalı BeeWSN yöntemini geliştirmişlerdir. Çalışmada düğümün kalan enerjisi, derecesi, düğüm hızı ve düğüm yönü bilgileri KB’nin seçilmesi sürecinde kullanılmıştır. KB süresi, küme sayısı, genel kontrol mesajları açısından yapılan testler sonucunda önerilen BeeWSN'nin, mevcut LEACH protokolüne göre yüksek performans gösterdiği kanıtlanmıştır. Yadav vd. (2018) Parçacık Sürü Optimizasyon (PSO) tekniğini kullanarak ağın ömrünü uzatmayı amaçlamışlardır. Yapılan benzetimlerde, LEACH algoritması ile 13000 paket gönderilirken, LEACH-PSO protokolü ile 20000 paketi iletilmiștir. Diğer bir çalışmada, Mehra vd. (2020) bulanık tabanlı geliștirilmiș küme başlığı seçimi (FBECS) adı verilen enerji bilinçli bulanık kümeleme protokolünü sunmuşlardır. KB’leri seçmek için algılayıcı düğümün uygunluk indeksini hesaplayan Bulanık Mantık yöntemi kullanılmıştır. Tasarlanan FBECS modelinde, LEACH protokolüne göre \%42.02 oranında daha fazla verinin iletimi sağlamıştır. Sivakumar ve Radhika (2018) ise geliştirdikleri Genetik Algoritma tabanlı Hiyerarşik yönlendirme protokolü LEACH-GA'nın performansını, LEACH protokolü ile karşılaștırmıșlardır. Ağın bașlangıç enerjisi ve küme başı olasılıkları değiștirilerek yapılan karşılaştırmalar sonucunda LEACH-GA, ağ ömrünü LEACH protokolüne göre \%54 oranında arttırmıştır. Thangaramya vd. (2019) KAA'larda QoS gereksinimlerini karşılamak için zeki makine öğrenmesi yöntemlerini kullanarak düğümlerin enerji tüketimini kontrol etmişlerdir. Bunun için bulanık kurallara sahip evrişimsel sinir ağları enerjinin modellemesinde kullanılmıștır. Küme başı ve ağ geçidi arasındaki uzaklık, algılayıcı dügüm ve küme başı arasındaki uzaklık, küme başının derecesi ve enerjisi verileri kullanılan sistemin ağ ömrünü arttırdığı tespit edilmiștir.

Özetle, sezgisel ve yapay zekâya dayalı algoritmaların KAA'larda LEACH yönlendirme protokolünün verimliliğini arttırmada önemli derecede başarı sağladı̆̆ı görülmektedir. $\mathrm{Bu}$ çalışmada da, stokastik global arama algoritmalarından olan Tavlama Benzetimi (Simulated Annealing - SA) algoritmasının LEACH protokolü üzerindeki performansı geliştirilen LEACH-SA yöntemi ile test edilmiştir. Tavlama Benzetimi yöntemi doğrusal ve konveks olmayan optimizasyon problemlerinin çözümü için sunulan iteratif meta sezgisel bir yöntemdir (Zhang vd., 2018). Tek ve çok amaçlı, kısıtlı veya kısıtlanmamıș optimizasyon problemleri ile ilgili bilim ve mühendislik alanlarında kullanılmaktadır. Çalışmada algılayıcı düğüm sayısı 100 olan bir KAA ortamı karmaşık, doğrusal 
olmayan ve matematiksel metotlar ile çözülemeyen bir optimizasyon problemi olarak seçilmiștir. Geliștirilen LEACH-SA yönteminin KAA'nın genel performansını nasıl etkilediği, enerji tüketimi, veri gönderimi, ağ üzerinde aktif/ölü düğüm sayıları ve algılayıcı başına düşen ortalama enerji miktarları MATLAB R2015b yazılımı ile modellenen KAA üzerinde incelenmiş ve sonuçları sunulmuştur.

Çalışmanın ilerleyen bölümleri şu şekilde organize edilmiştir; materyal ve yöntem bilgileri Bölüm 2'de sunularak, KAA ve LEACH protokolü ve Tavlama Benzetimi algoritmaları ile ilgili ayrıntılı bilgilere yer verilmiștir. Geliștirilen LEACH-SA yöntemi Bölüm 3'te açıklanmış, çalışmaya ait test sonuçları ise Bölüm 4'de değerlendirilmiștir.

\section{Materyal ve Metot (Material and Method)}

\subsection{Kablosuz Algılayıcı Ăg (Wireless Sensor Network)}

KAA, ortak bir amaca ulaşmak için birbirleriyle işbirliği içinde çalışan, belirli bir bölgeye dağıtılmış algılayıcı dügümlerin koalisyonu olarak tanımlanabilir (Ramluckun vd., 2020). Bir KAA ortamında bulunan algılayıcı düğümler, bulundukları ortamdaki bilgileri toplamak ve önceden belirlenmiş bölgelere iletebilmeleri için farklı yapılarda tasarlanmışlardır. Farklı görevlere sahip dügü̈mlerden oluşan bir KAA yapısı Şekil 1'de verilmiştir. Şekil.1'de gösterilen AD (Algılayıcı Düğüm), çevresindeki olayları algılayabilen küçük boyutlu bir cihazdır. Küçük boyutlu olmasının getirdiği tasarım sınırlamalarından dolayı, sınırlı olarak hesaplama, depolama ve haberleşme işlevlerine sahiptir. AD'ler kendi aralarında haberleşebilirler ya da doğrudan KB'lere ve AG (Ağ Geçidi)'ye veri gönderebilirler. KB'ler ise bulundukları küme içindeki AD'lerden topladıkları verileri AG'ye veya AG'ye ulaştırması için başka bir KB'ye iletmekten sorumludurlar. Her veri aktarımı çevriminde farklı bir düğüm KB seçilebilir. Genellikle ağın dış bölgesinde bir yere konumlandırılan AG ise ağdan toplanan verileri alarak son kullanıcıya ulaştırma görevini yerine getirir (Dong vd., 2011).

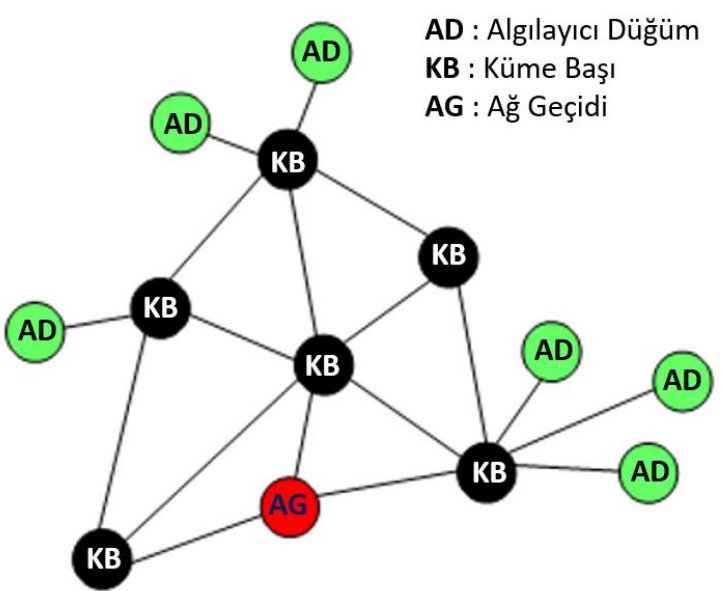

Şekil 1. KAA Yapısı ve Algılayııı Düğüm Tipleri (WSN Structure and Sensor Node Types)

\subsection{LEACH Protokolü (LEACH Protocol)}

Heinzelman, Chandrakasan ve Balakrishnan (2000) tarafından önerilmiştir. Hiyerarşik bir yönlendirme protokolüdür (Ihsan vd., 2019). LEACH protokolünü uygulayan bir KAA ortamı Şekil 2'de verilmiştir. LEACH protokolü kurulum fazı ve kararlı durum fazı olmak üzere iki aşamada gerçekleşir. Kurulum fazında algılayıcı düğümlerden biri $\mathrm{AG}$ düğümünden iletileri alan $\mathrm{KB}$ olarak görev yapar ve aldığı bu iletileri tüm algılayıcı düğümlere iletir (Sivakumar vd., 2018). Algılayıcı düğümlerden kümeler oluşturulur. Ardından küme içinde bulunan dügümler arasından KB seçilir. 


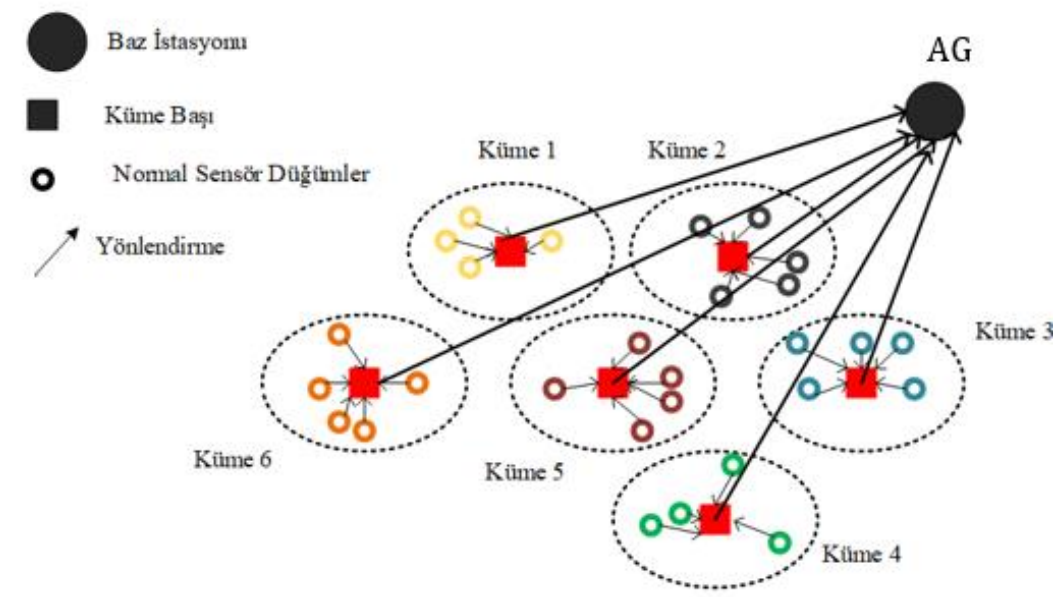

Şekil 2. LEACH Protokolü Modeli (The Model of LEACH Protocol)

Kararlı durum fazında kümede bulunan algılayıcı düğ̈mler verileri KB’ye gönderir. KB ise topladığı bu verileri AG'ye gönderir (Asha vd., 2018). KB seçimi, düğ̈mün coğrafi konumu ve kalan enerjisi dikkate alınmadan rastgele gerçekleştirilir (Anastasi vd., 2009).

Bir düğümün KB olarak seçilmesi sırasında, düğüm 0 ile 1 arasında rasgele sayı üretir. Üretilen sayı eşik Denklem (1)'den elde edilen $T(n)$ değerinden düşük ise, o zaman dügüm KB olarak tanımlanır (Shieh vd., 2011, Sodeifian vd., 2017).

$$
T(n)=\left\{\begin{array}{ll}
\frac{p}{1-p \cdot\left(\operatorname{rmod}\left(\frac{1}{p}\right)\right)} & ; \quad \forall n \in G \\
0 \quad & \text { aksi takdirde }
\end{array}\right\}
$$

Burada; $p$, küme başı seçilme olasılığı ve $r$ veri iletiminin gerçekleştirildiği çevrim sayısıdır.

LEACH protokolünde enerji tüketimi modeli birincil radyo yayılım modeline göre gerçekleşmektedir. Alıcı ve Gönderici düğümler arasında gerçekleșen birincil radyo yayılım modeline ait şema Şekil 3'de verilmiştir (Heinzelman vd., 2000).

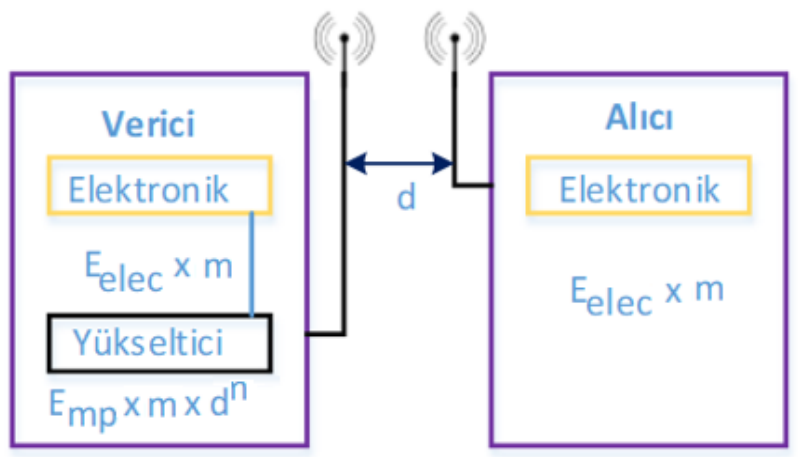

Şekil 3. Birincil Radyo Yayılım Modeli (First Order Radio Model)

LEACH protokolünde uygulanan enerji harcama modeline ait eșitlikler Denklem (2)'de verilmiștir (Anastasi vd., 2009). Burada; $m$ iletilecek bit sayısı, $E_{T x}$ bir algılayıcı düğümün komşusuna veri iletirken düğüm tarafından harcanan enerji, $\varepsilon_{f s}$ boşluktaki enerji kaybı, $E_{m p}$, enerji transferinin amplifikasyon katsayısı, $E_{\text {elec }}$ verici veya alıcı devreleri çalıştırmak için bit başına harcanan enerjidir ve boş alan enerjisidir. $d$ iletim mesafesidir. Öklid uzaklığına göre hesaplanır. $d^{2}$, boşluktaki güç kaybıdır, $d^{4}$, çok yollu solma güç kaybıdır [9].

$$
E_{T x}(m, d)=\left\{\begin{array}{lc}
m E_{\text {elec }}+m \epsilon_{f s} d^{2} & d<d_{0} \\
m E_{\text {elec }}+m \epsilon_{m p} d^{4} & d \geq d_{0}
\end{array}\right\}
$$


$d_{0}$, alıcı ve verici arasındaki uzaklıktır ve Denklem (3)'e göre hesaplanır [14].

$$
\mathrm{d}_{0}=\sqrt{\frac{\epsilon_{\mathrm{fs}}}{\epsilon_{\mathrm{mp}}}}
$$

\subsection{Meta-Sezgisel Algoritmalar (Meta-Heuristic Algorithms)}

Meta-Sezgisel algoritmalar, bir problemin çözümünde klasik yöntemler çok yavaş kaldığında, bu problemi daha hızlı çözmek ya da kesin sonuca ulaşılamadığı durumlarda, verilen şartlar altında en yakın çözüme ulaşmak için tasarlanmış algoritmalardır. Meta-Sezgisel algoritmaların matematiksel optimizasyon algoritmalarından ayrıldığı nokta, meta-sezgisel algoritmaların tüm çözüm kümesini taramak yerine çözüm kümesine sezgisel yaklaşarak en iyiye yakın çözümü aramasıdır (Çelik vd., 2019). Sezgisel algoritmaların temeline bakıldığında bir deneme yanılma yöntemi olduğu görülür (Yang vd., 2015). Literatürde genel kabul görmüş temel meta-sezgisel algoritmalar vardır. Bunlara; Genetik Algoritma, Parçacık Sürü Optimizasyonu(Kennedy and Eberhart, 1995), Yapay Arı Kolonisi (Karaboğa, 2005), Yerçekimi Algoritması (Rashedi vd., 2009) ve Karınca Kolonisi algoritması (Dorigo vd., 1997) örnek olarak verilebilir.

Literatürde sezgisel algoritmaların birçok endüstriyel ve bilimsel problemin çözümünde kullanıldığı görülmektedir. Meta-Sezgisel arama algoritmaları, jeotermal güç santrallerinin ekserji verimliliğini arttıracak parametrelerin belirlenmesinde (Özkaraca vd, 2017; Özkaraca, 2018; Özkaraca vd. 2018, Özkaraca vd, 2019), PV hücre parametrelerinin tanımlanmasında (Yang vd. 2020), düzlemsel çelik çerçeve yapılarının optimum tasarımlarının bulunmasında (Kaveh vd. 2020), graf renklendirme problemlerinde (Mostafaie vd., 2020) ve hareketli robot yollarının planlanması (Ab Wahab vd, 2020) gibi çok farklı alanlarda kullanılmıştır. Bununla birlikte meta-sezgisel algoritmaların geniş alanda kabul görmesi, son yıllarda farklı meta-sezgisel algoritmaların da geliştirilmesini sağlamaktadır.

\subsubsection{Tavlama Benzetimi (Simulated Annealing)}

Tavlama Benzetimi yöntemi, temelinde katıların tavlama sürecindeki atomik hareketlerini taklit eden meta sezgisel bir yöntemdir. Tavlama, bir maddede düşük enerji seviyelerine erişmek için kullanılan termal bir işlemdir. Bu işlemde, ilk önce sıcaklık, bir katı için erime sıcaklığına çıkarılır ve daha sonra malzeme soğutulur. Tavlama sürecinde soğuma hızı atomların yer değiştirmelerine izin verecek ölçüdeyse, atomlar en düşük iç enerji ve en yüksek kararlılık durumuna rasgele hareketler ile geçme eğilimindedirler (Shieh vd., 2011). Bu rasgele dalgalanmalar, malzemenin yerel enerji minimumundan kaçmasına izin verecek ve malzemedeki termal stresi karakterize eden bir miktar artık enerji ile yapılandırılmış olarak soğutacaktır (Sodeifian vd., 2017).

Metropolis vd. (1953), optimum çözümlerle ilişkilendirilen en düşük enerji durumunu bulmak için tavlama işlemini Monte Carlo olasılık mekanizmalarını kullanarak matematiksel olarak ifade etmişledir (Shieh vd., 2011). Standart Monte Carlo algoritması, sadece düşük enerjili bir duruma hareketi kabul ederken, Metropolis prosedürü, daha yüksek enerjili bir durumun da olasılıkla kabul edilmesini mümkün kılmıştır (Javidrad vd., 2017). Kirkpatrick vd. (1983) ve Cerny (1985) ise bu fikri, kombinasyonel optimizasyon problemleriyle başa çımak amacıyla sezgisel bir yönteme dönüștürmüștür (Aguitoni vd., 2019).

Tavlama Benzetimi algoritması Şekil 4'te verilen 6 aşama ile ifade edilebilir. Bu durumu problemlere uyarladığımızda; geniş bir çözüm aralığı içeren problemlerde, yüksek sıcaklık değerinden başlanarak çözüm aranmaya başlanır, sıcaklık kademeli düşürülerek, rastgele olacak șekilde komşu çözümlere bakılır. Yeni bulunan komşu çözüm, önceki amaç fonksiyonundan daha iyiyse kabul edilir. Bu, minimizasyon problemi ise, en düşük değere bakılır. Arama yapmaya devam edilir. Komşu çözümlere bakılarak yapılan arama işleminde, daha kötü bir çözüm bulunursa, bu çözümün kabul olasılıklarına bakılarak değerlendirmeye alınır. Çözümlerin kabul olasılıkları Denklem (4)'e göre değerlendirildikten sonra kademeli azaltılan sıcaklık ile komşu çözümlerden aramaya devam edilir. Son sıcaklık değerine ulaşıldığında o ana kadar bulunan en iyi çözüm, amaç fon ksiyonu olarak kabul edilir (Uysal vd., 2019).

$$
X_{i+1}=\left\{\begin{array}{cc}
X_{\text {yeni },} & \text { exp }\left(-\frac{\Delta \mathrm{f}}{T}\right)>r \\
X_{i}, & \text { aksi takdirde }
\end{array}\right\}
$$


Kabul olasılığına bakılmasının amacı, bulunan ilk yerel minimumla çözümün sınırlandırılmamasıdır. Algoritmada amaç fonksiyonunun minimum değeri aranırken bölgesel olarak elde edilen en iyi değer yerel minimum çözümdür. Eğer ilk bulunan yerel minimum değeri çözüm kabul edilirse, bu değerden daha iyi çözüm olan evrensel en iyiye ulaşma olasılığı engellenmiş olur. Algoritmanın her zaman evrensel en iyi çözüme ulaşması beklenen bir durum değildir. Algoritmanın en düşük sıcaklığa kadar yaptığı aramada bulduğu en iyi çözüm kabul edilir.

\begin{tabular}{l} 
Adım 1 \\
• Başlangıç sıcaklığını ayarla ve i=0 için rasgele bir başlangıç çözümü oluştur \\
\hline Adım 2 \\
• Başlangıç durumu için amaç fonksiyonu hesapla ve bir durma koşulu \\
sağlanana kadar döngü başlat \\
\hline Adım 3 \\
•i+1 için rasgele bir komşu çözüm üret \\
\hline Adım 4 \\
•i+1 çözümü için amaç fonksiyonu hesapla \\
\hline Adım 5 \\
•Çözüm (i) < Çözüm(i+1) ise: yeni çözüme geç \\
Çözüm(i) > Çözüm (i+1): yeni çözüme geçme olasılı̆ını hesapla \\
\hline Adım 6 \\
\hline •Kabul edilebilir bir çözüm bulunana kadar veya minimum sıcaklığa ulaşana \\
kadar 3-5. adımları tekrarla
\end{tabular}

Şekil 4. Tavlama Benzetimi Algoritmasının Aşamaları (Steps of the Simulated Annealing Algorithm)

\section{LEACH-SA Yöntemi (LEACH-SA Method)}

Çalışmada, öncelikle MATLAB R2015b yazılımı kullanılarak LEACH yönlendirme protokolü grafik kullanıcı arayüz tabanlı olarak 100 düğümlü bir KAA için Şekil 5 (a)'da gösterildiği gibi modellenmiştir. Modelde algılayıcı düğ̈̈mler 100m x100m alan içerisine rasgele dağıtılmıştır. Ayrıca modelde merkezi bir noktaya ağ geçidi görevi gören bir cihaz yerleștirilmiștir. Ağın bu modelinde düğümler arasında herhangi bir kümeleme ișlemi yapılmamıştır. Bununla birlikte Şekil 5 (b)'de oluşturulan ağ modelinin bir veri aktarımı çevrimi için LEACH protokolüne göre kümelenmiş şekli verilmiştir. Bu kümeleme işlemi her bir çevrimde yeniden oluşturulmakta ve en uygun küme başı dügüm LEACH protokolü prosedürlerine göre seçilmektedir. Örnek olarak Şekil 5 (b)'de kümeleme aşamasında 11 adet küme oluşturulmuştur. Kümeye dahil olan algılayıcı dügü̈mler verilerini KB'ye iletirler, daha sonrasında ise KB'ler topladıkları bu verileri merkezi konumda bulunan AG'ye gönderirler. Böylece ilk veri aktarım çevrimi tamamlanarak yeni çevrim için ağ hazır olur. Hazırlanan KAA test modelinde, her bir veri iletimi çevriminde yaşanan enerji tüketiminin hesaplanması aşamasında kullanılan parametreler ve başlangıç değerleri Tablo 1'de verilmiştir.

Tablo 1. LEACH Birinci Dereceden Radyo Modeli Test Parametreleri (LEACH First Order Radio Model Test Parameters)

\begin{tabular}{ll}
\hline Parametre & Değer \\
\hline Başlangıç Enerjisi (Eo) & $0.5 \mathrm{~J} /$ düğüm \\
Verici Elektronik (Eelec) & $50 \mathrm{~nJ} / \mathrm{bit}$ \\
Alıcı Elektronik (Eelec) & $50 \mathrm{~nJ} / \mathrm{bit}$ \\
Veri Paketi Büyüklüğü (l) & $4000 \mathrm{bit}$ \\
Enerji Aktarım Katsayısı (Efs) d $<\mathrm{d}_{0}$ için & $10 \mathrm{pJ} / \mathrm{bit} / \mathrm{m}^{2}$ \\
Boşluktaki Enerji Kaybı (Emp) d $>\mathrm{d}_{0}$ için & $0.0013 \mathrm{pJ} / \mathrm{bit} / \mathrm{m}^{4}$ \\
Küme bașı oranı (p) & 0.1 \\
\hline
\end{tabular}


(a)

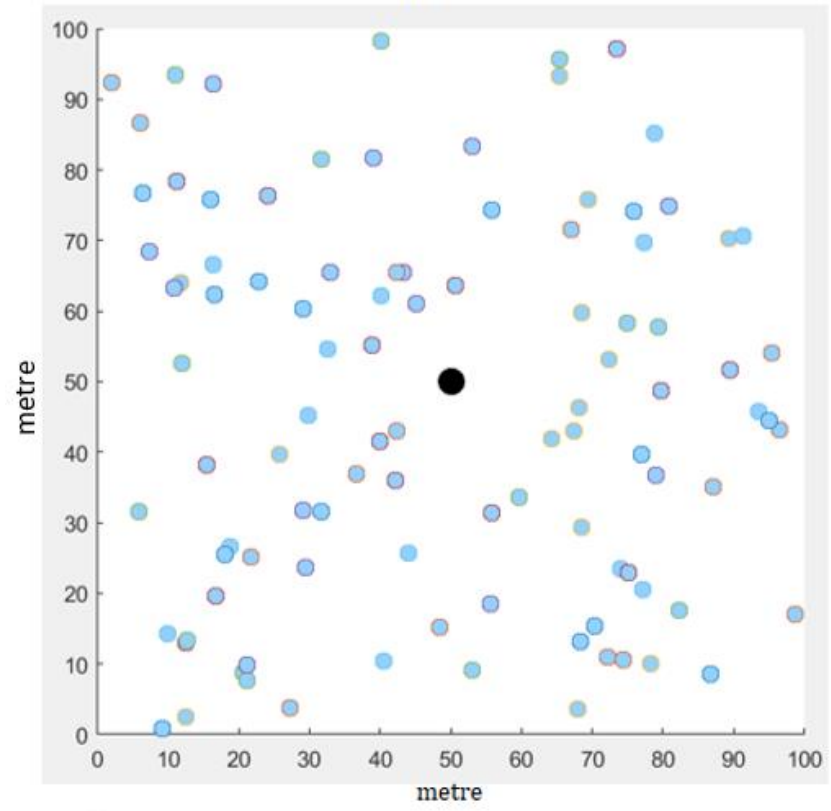

(b)

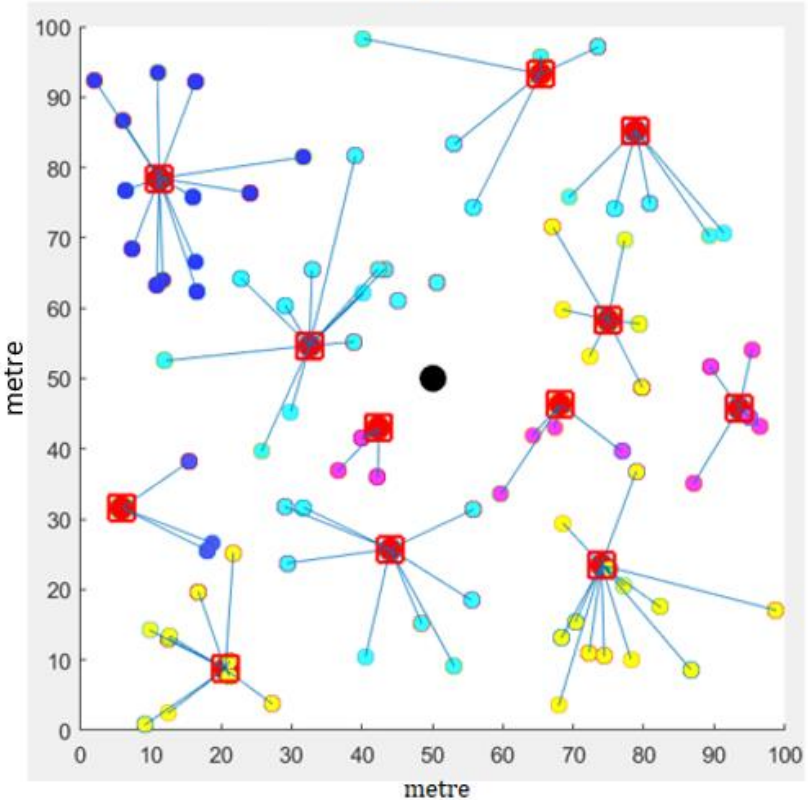

Ağ Geçidi

n. Tur için Küme Bașı Seçilen Düğüm

- Bir Kümeye Dahil Olan Algllayıcı Dügüm

Şekil 5. (a) n=100 Algılayıcı Düğüme Sahip Kümelenmemiş Test Ağı (Test Network Including n=100 Sensor Node without Clustering) (b) Kümelenmiş Ağ Yapısı (Clustering Network Structure)

Daha sonra, geliştirilen modellemede enerji verimliliğini optimize etmek için TB algoritması dâhil edilmiştir. LEACH-SA olarak adlandırılan bu yöntemde, LEACH protokolü her bir turda seçilen KB sayısı ve dügü̈mlerinin seçilmesi görevini yerine getirirken, TB algoritması ise seçilen bu düğümlerin o veri aktarımı için en az enerji tüketimini sağlayacak daha iyi düğ̈umlerle değiştirilmesini gerçekleştirmiştir.

Çalışmanın amaç fonksiyonu, her bir veri aktarım çevriminden sonra algılayıcılarda kalan toplam enerjidir ve Denklem (5)'de verilmiştir.

$f\left(x_{i}\right)=f\left(x_{i-1}\right)-\sum_{i=1}^{K B n} E_{T X(S i \rightarrow K B n)}(m, d)+\sum_{i=1}^{K B n} E_{K B n}+E_{T X(K B n \rightarrow A G)}(m, d)+\sum_{i=1}^{c} E_{T X(S c \rightarrow A G)}(m, d)$

Burada $K B n$ Küme başı sayısını, $E_{T X(S i-K B n)}$ i. algılayıcı düğümden n. KB'ye veri gönderilirken harcanan enerjiyi, $E_{K B n}$ n. KB'nin verileri alırken harcadığı enerjiyi, $\left.E_{T X(K B n}-A G\right)$ n. küme bașından AG'ye veriler gönderilirken harcanan 
enerjiyi, $c$ her hangi bir kümeye dahil olmayan algılayıcıları, $E_{T X(S c-A G)}$ i. algılayıcı dügüumden AG'ye veri gönderimi sırasında harcanan enerjiyi ifade eder.

Tavlama Benzetimi algoritması ile KAA'da enerji verimliliği optimizasyonu yapılırken kullanılan kısıtlamalar aşağıda verilmiştir.

- $\quad$ N algılayıcı düğüm kümesi olmak üzere, KB düğümü N kümesinin bir elemanıdır (KB $\in N)$.

- $\quad \mathrm{M}$ daha önce $\mathrm{KB}$ seçilen dügümlerin kümesi olmak üzere, yeni KB M kümesinin bir elemanı olamaz (KByeni $\notin \mathrm{M}$ )

- $\quad$ M kümesi her r. turda sifırlanır ( $\mathrm{r} \bmod \mathrm{KB}$ sıfırla = 0) için $(\mathrm{M}=\varnothing)$

- Seçilen algılayıcı düğüm enerjisi 0'dan büyük olmalıdır $(\mathrm{E}>0)$.

Çalışmada geliştirilen LEACH-SA algoritmasının akış diyagramı Şekil 6'da verilmiştir. Akış diyagramına göre işlem adımları;

1. Maksimum tur sayısı için KAA'ın çalışmasını başlat

2. Tavlama Benzetimi parametrelerini tanımla (Tbasla, Tson, sk).

3. KAA için mevcut durumu kaydet.

4. N kümesinden, aynı anda M kümesine dahil olmayan algılayıcılardan yüzde değerine göre KB düğüm seç.

5. Seçilen KB'lere göre kümeleme işlemi gerçekleştirilir.

6. Denklem 5'de verilen amaç fonksiyonuna göre enerji tüketimini hesapla

7. Hesaplanan değeri en iyi değer olarak kabul et.

8. Tavlama Benzetimi ile $i+1$. iterasyon için yeni komşu bir düğümü KB olarak seç ve mevcut listedeki bir KB ile yer değiștir. Daha sonra yeni durum için ağdaki düğümleri kümelere dağıt ve enerji tüketimini hesapla

9. Ĕ̆er Etop(i+1), Etop(i) enerji tüketimi değerinden daha küçük ise, yeni bulunan değeri ve küme başı listesini kaydet, Değilse yeni kötü durumu kabul edip etmeme durumu için $r s$ rasgele sayısını üret. $r s<\exp (-\Delta E T o p / T)$ ise bu durumu yeni durum olarak kabul et.

10. Eğer minimum sıcaklık değerine ulaşıldı ise döngüden çık ve bulduğun en az enerji tüketimine göre KAA'yı güncelle. Minimum sıcaklık değerine ulaşılamadı ise Tbasla değerini sk kadar azalt ve tekrar döngüye gir.

LEACH-SA yönteminde, kullanılan Tavlama Benzerimi parametreleri ve değerleri Tablo 2'de verilmiştir.

Tablo 2. Tavlama Benzetimi Parametreleri (Parameters of Simulated Annealing)

\begin{tabular}{ll}
\hline Parametre & Değer \\
\hline Başlangıç Sıcaklığg $\left(\mathrm{T}_{\text {başlangıç}}\right)$ & 100.000 \\
Son Sıcaklık ( $\left.\mathrm{T}_{\text {son }}\right)$ & 0.1 \\
Soğuma Katsayısı (sk) & 0.99 \\
\hline
\end{tabular}




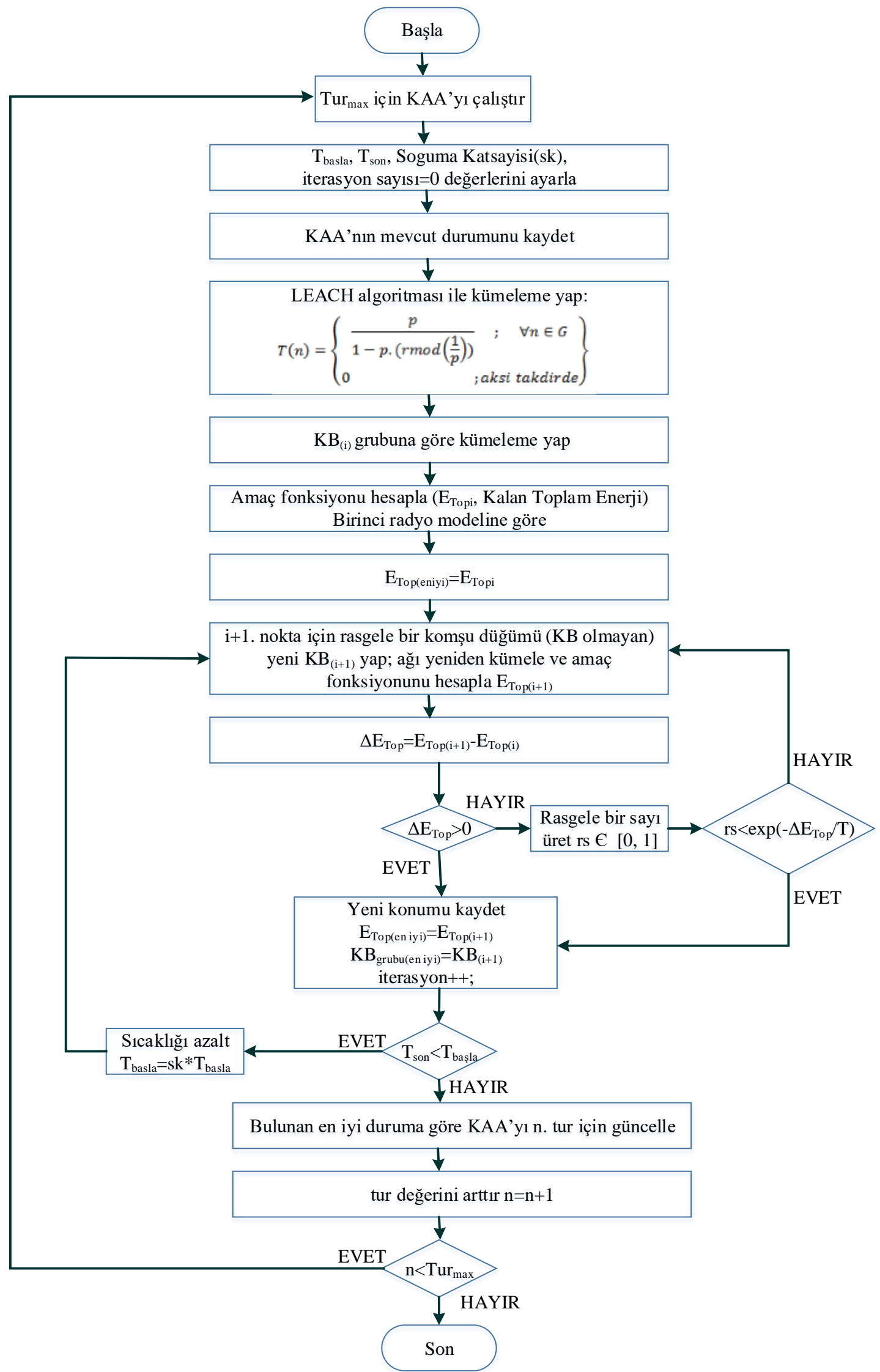

Şekil 6. LEACH-SA ile Enerji Optimizasyonu Akış Diyagramı (Energy Optimization Flow Chart with LEACH-SA) 


\section{Deneysel Sonuçlar (Experimental Results)}

Şekil 7'de, tasarlanan KAA modeline göre, enerji tüketimi optimizasyonu algoritmasının çalıştırılması sırasında tek bir veri aktarımı çevrimi için ağda kalan toplam enerji miktarının aranması grafiksel olarak verilmiștir. Test ağı modelinde her bir algılayıcı dügümün başlangıç enerjisi Tablo 1'de de verildiği gibi 0.5J kabul edilmiştir. Buna göre 100 dügüum için ağdaki toplam enerji $100 * 0.5$ J'den 50J'dür. Ancak bu enerji her bir veri aktarımı çevriminde azalmakta ve en sonunda 0'a inmektedir. Şekil 7'de verilen grafiğe göre ağın veri aktarımına başlamadan önceki durumu için toplam enerjisinin 44.898J'dir. Burada istenen, oluşturulacak kümelemenin veri aktarımı sırasında en az enerjiyi tüketecek şekilde tasarlanmasıdır. Bu amaçla geliştirilen SA algoritması ile 1384 iterasyonda en iyi değeri (yerel maksimum) bulabilmek amacıyla komşu küme başı grupları için amaç fonksiyonunu yeniden hesaplamıştır. Test sonucunda $\mathrm{x}=66$. iterasyonda $\mathrm{Y}=44.89$ ile veri aktarım çevrimi sonucunda kalacak en yüksek enerjili durumu kaydetmiştir. Tavlama benzetimi algoritmasının, yapısı gereği bazı iterasyonlarda daha kötü durumlara geçebilme eğiliminde olduğu grafikte de görülmektedir. Bunun başlıca nedeni daha kötü bir durumdan sonra, bir sonraki iterasyonda çok daha iyi bir durumun çıkabilme olasılığıdır. Kullanılan test ağı modelinde bu işlem her bir veri aktarım çevrimi için tekrar edilmekte ve kalan dügümler arasında kurulabilecek en iyi kümenin (en az enerji harcayacak) seçimi yapılmaktadır.

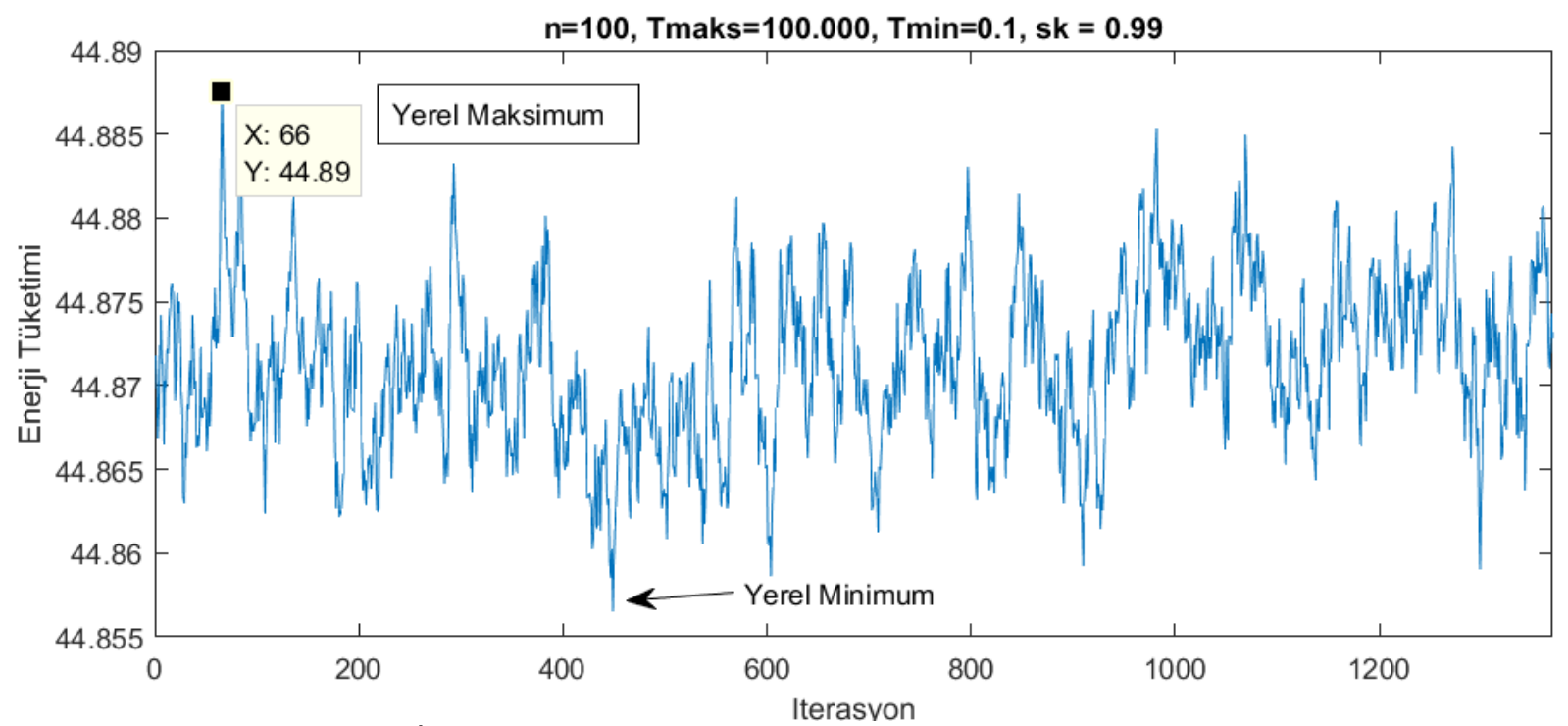

Şekil 7. LEACH-SA ile En İyi Durumun Aranması (Searching for the Best Situation with The LEACH-SA)

Şekil 8'de LEACH-SA yönteminde TB algoritmasının bulduğu enerji kazanç değerleri yığınsal çubuk grafik ile verilmiştir. Grafiğe göre her bir turda LEACH protokolünün belirlediği KB’ler sonucunda harcanacak enerji miktarı mavi renkle, LEACH-SA yönteminin çalıștırılması sonucunda bulunan yeni KB'lere göre kazanılan enerji miktarı kırmızı renk ile gösterilmiştir. Şekil 8’e göre; 40. turda LEACH protokolü ile seçilen KB'lerin çalıştırılması sonucu toplam algılayıcı enerjisi 46.85 J'ye düşecekken, LEACH-SA yöntemi ile bu KB'lerin komşulukları aranarak, yeni bir KB listesi oluşturulmuş ve değer 46.874'de kalmıştır. 40.tur için 0.024J'lik bir enerji kaybı engellenmiştir. Ancak burada belirtilmelidir ki, burada kazanılan kazanç değeri sadece 40. turu değil kendisinden sonra gelecek diğer turları ve dolayısıyla tüm performansı etkilemektedir. Çünkü bir sonraki LEACH ya da LEACH-SA yöntemi küme başı seçimleri daha önceki turların en iyi seçimleri üzerine çalışmakta ve yeni turlar için olasılıklar değişmektedir. Diğer taraftan algoritma LEACH protokolünün bulduğu değerden daha iyi bir sonuç bulamazsa, LEACH ile bulunan küme başı listesi en iyi liste olarak kabul edilerek programa devam edilmektedir. Örnek olarak 43. turda LEACHSA ile daha iyi bir sonuç elde edilememiş ve enerji kazanılamamıştır. 


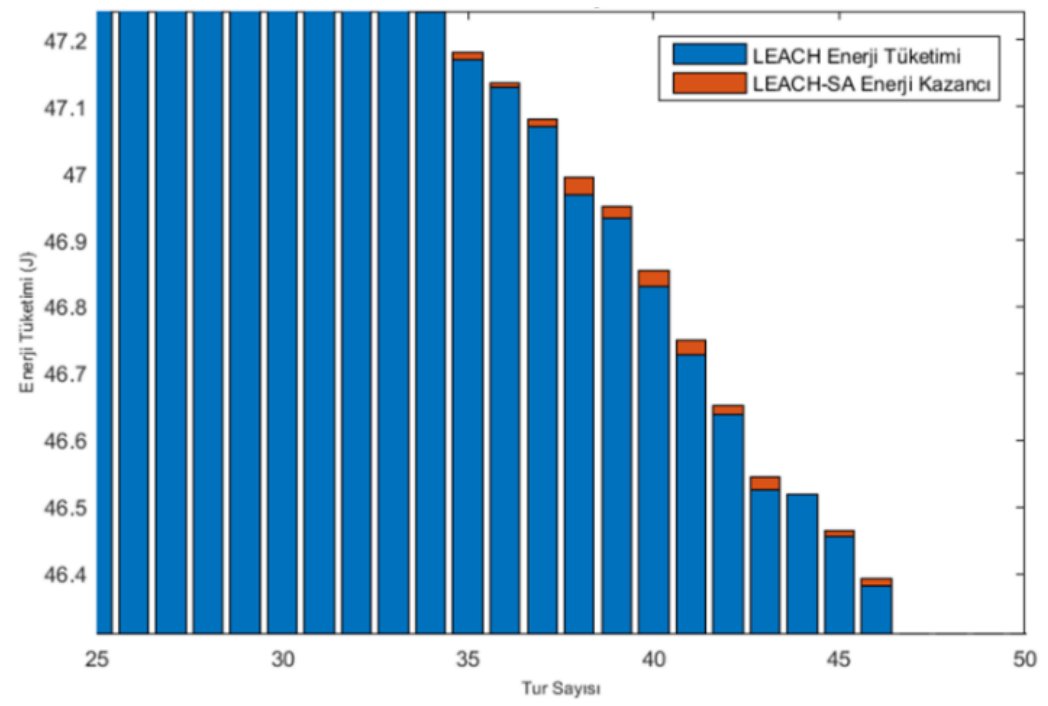

Şekil 8. LEACH-SA yönteminde enerji kazançları (Energy gains in LEACH-SA Method)

\subsection{KAA Enerji Kaybı (WSN Energy Loss)}

Çalışmada, KAA ortamında her bir veri gönderimi çevriminde harcanan enerji miktarı hesaplanarak, ağın veri gönderim çevrimi sayısının arttırılması amaçlanmıştır. $n=100$ için Şekil 5'de verilen ağ modeline göre elde edilen enerji tüketimi test sonuçları Șekil 9'da gösterilmiștir. Başlangıçta ağdaki algılayıcı düğümlerin 50j'dür. Bu enerji her bir veri aktarımı çevriminde azalmaktadır. Test sonuçlarına göre; test ağında veri aktarımı sırasında LEACH protokolü kullanıldığında en fazla 635 çevrim sonunda algılayıcı düğümlerin enerjisi tükenerek 0 olmuştur. Diğer taraftan, çalışmada geliştirilen LEACH-SA yöntemi kullanıldığında veri gönderim çevrimi 1156'ya çıkmıştır. Sonuç olarak, LEACH protokolüne kıyasla LEACH-SA yöntemi veri gönderim çevrimleri açısından $\% 82$ oranla daha uzun hayatta kalmıştır.

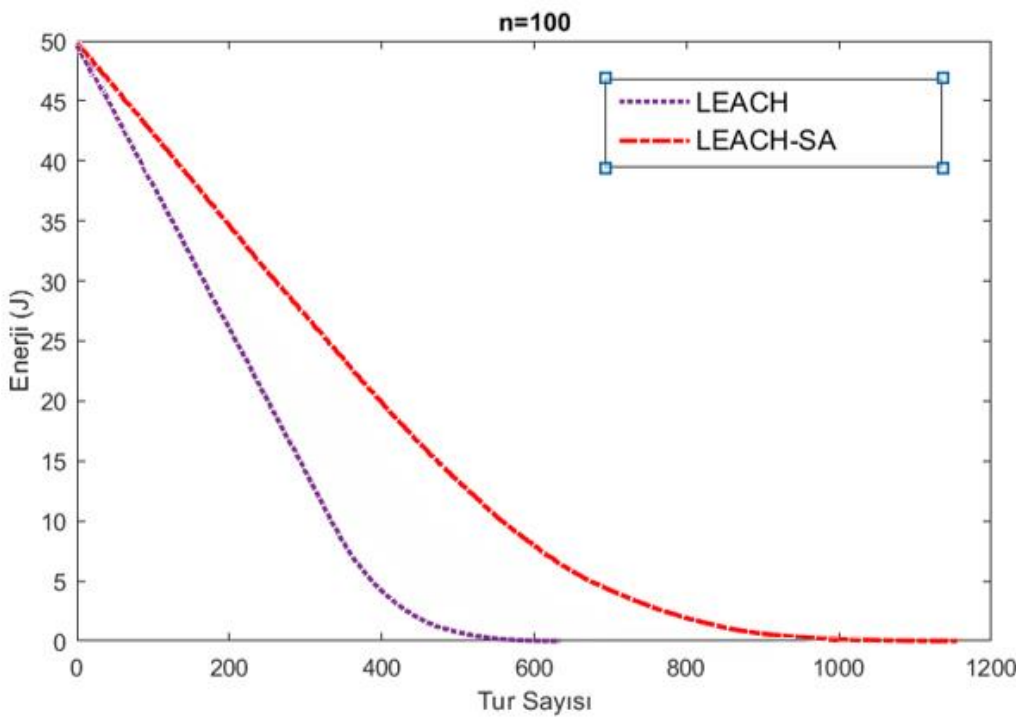

Şekil 9. Enerji Kaybı Test Sonuçları (Test Results of Energy Loss)

\subsection{KAA Veri Gönderimi (WSN Sending Data)}

Test ağı modelinde her bir algılayıcı düğümün her bir veri çevriminde Tablo 1'de de verildiği gibi 4000bit veri aktarımı yaptığı kabul edilmiştir. Buna göre, her bir tur sonunda gönderilen toplam veri paketi sayıları Șekil 10'da grafiksel olarak sunulmuştur. Grafiğe göre; LEACH protokolünde 635 çevrim sonucunda toplamda 43881 veri paketi gönderilirken, LEACH-SA yönteminde 1156 çevrimde \%72.2 artışla 75584 veri paketi gönderilmiştir. 


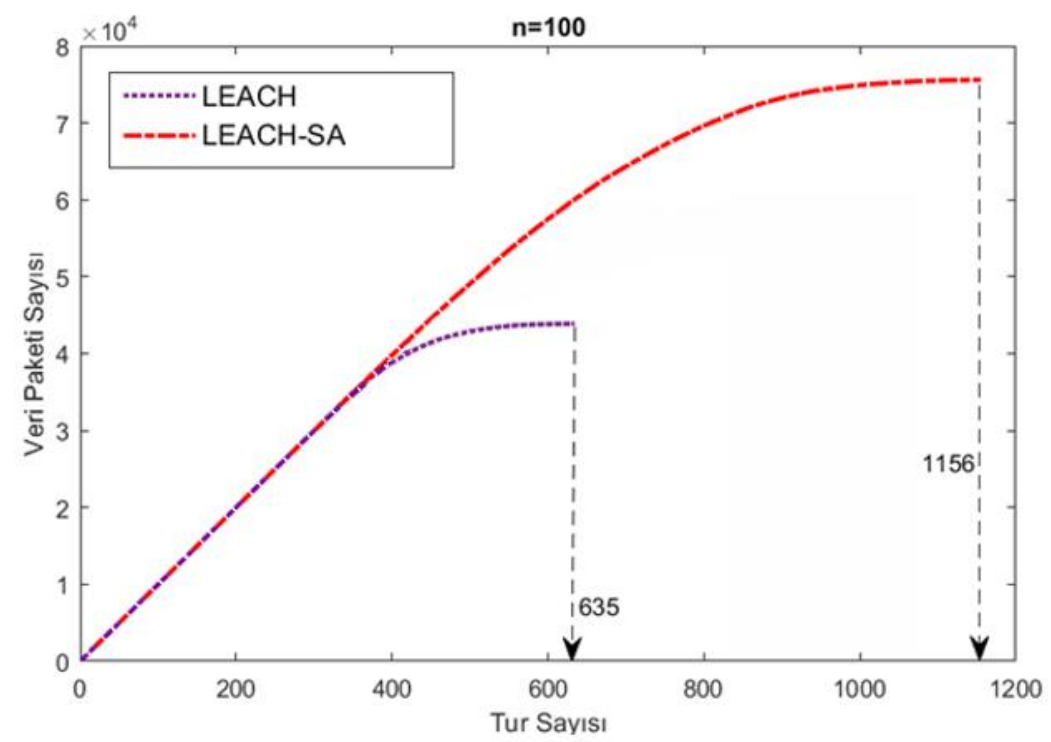

Şekil 10. Veri gönderimi test sonuçları (Test Results of Sending Data)

\section{Sonuçlar (Results)}

Bu çalışmada, KAA'ların topladıkları verileri, ağın çıkış noktasını oluşturan AG'ye göndermeleri sırasında harcadıkları enerjinin optimize edilmesi amaçlanmıștır. Bu amaçla, çalıșmada meta sezgisel bir algoritma olan Tavlama Benzetim algoritmasına dayalı bir yöntem geliştirilmiştir. LEACH-SA olarak adlandırılan bu yöntemde her bir çevrim sırasında verilerin toplanması görevini gerçekleştirecek olan küme başı düğümleri ve sayıları LEACH protokolü ile seçilmiş, daha sonra bu düğümlerin komşulukları incelenerek optimize edilmesi Tavlama Benzetimi yöntemi ile gerçekleştirilmiştir. Test sonuçlarına göre; Tavlama Benzetimi algoritmasının özellikle algılayıcı sayısı fazla olan ağlarda LEACH protokolü ile birlikte kullanıldığında, LEACH protokolünün verimliliğini enerji tüketimi açısından \%82 ve veri paketi iletimi açısından \%72.2 oranında arttırdığı görülmüştür. Ancak, çalışma sonuçları tasarlanan KAA modeli ile sınırlıdır. Her bir KAA modelinde algılayıcılar belirli bir bölgeye rasgele konumlarda dağıtıldıklarından her bir ağ yapısında başarım değeri farklılık gösterecektir.

\section{Çıkar Çatışması (Conflict of Interest)}

Yazarlar tarafından herhangi bir çıkar çatışması beyan edilmemiştir. The authors declared no conflict of interest.

\section{Kaynaklar (References)}

Ab Wahab, M. N., Mezinani, S. N., Atyabi, A., "A comparative review on mobile robot path planning: Classical or meta-heuristic methods?", Annual Reviwes in Control, 50, pp. 233-252, 2020.

Aguitoni, M.C., Pavao, L.V., Ravagnani, M., 2019. Heat Exchanger Network Synthesis Combining Simulated Annealing and Differential Evolution. Energy, 81, 654-664.

Ahmad, M., Ikram, A.A., Lela, R., Wahid, I., Ulla, R., 2017. Honey Bee Algorithm-Based Efficient Cluster Formation and Optimization Scheme in Mobile Ad Hoc Networks. International Journal of Distributed Sensor Networks. 13(6), 1-12.

Anastasi, G., Conti, M., Francesco, M., Passarella, A., 2009. Energy Conservation in Wireless Sensor Networks: Ad Hoc Networks, 7, 537-568.

Asha, G.R., Gowrishankar, 2018. Energy Efficient Clustering and Routing in a Wireless Sensor Networks: Procedia Computer Science. 134, 178-185.

Cerny, V.,1985. A Thermodynamical Approach to The Traveling Salesman Problem: An Efficient Simulation Algorithm. Journal of Optimization Theory and Applications, 45(1), 41-51.

Çelik, Y., Yildiz, İ., Karadeniz, A. T., "Son Üç Yılda Geliştirilen Metasezgisel Algoritmalar Hakkında Kısa Bir İnceleme”, European Journal of Science and Technology, pp. 463-477, 2019

Dong, Y., Zhang, S., Dong, Z., Cui, Y., 2011. ZigBee based Energy Efficient Reliable Routing in Wireless Sensor Network: Study and Application. In IEEE 3rd International Conference on Communication Software and Networks. 464-467.

Dorigo, M.,and Gambardella, L. M. "Ant colonies for the traveling salesman problem", BioSystems, vol. 43, no. 2, pp. 73-81, 1997.

Erdelj, M., Mitton, N., Natalizio, E., 2013. Applications of Industrial Wireless Sensor Networks. Güngör, Ç., Hancke, G.P., (Edt.), Industrial Wireless Sensor Networks içinde (s.3-27) Taylor \& Francis.

Heinzelman, W.R., Chandrakasan, A., Balakrishnan, H., 2000. Energy-Efficient Communication Protocol for Wireless Microsensor Networks. Proceedings of the 33rd Annual Hawaii International Conference on System Sciences. 2, 10.

Ihsan, A., Saghar, K., Fatima, T., Hasan, O., 2019. Formal Comparison of LEACH and Its Extensions. Computer Standards \& Interfaces, 119-127. 
Javidrad, F., Nazari, M., 2017. A New Hybrid Particle Swarm and Simulated Annealing Stochastic Optimization Method. Applied Soft Computing, 60, 634-654.

Karaboğa, D., "An Idea Based On Honey Bee Swarm For Numerical Optimization”, Technical Report-TR06, Erciyes University, Engineering Faculty, Computer Engineering Department, 2005.

Kaveh, A., Hamedani, K. B., Hosseini, S., M., Bakhshpoori, T., "Optimal design of planar steel frame structures utilizing metaheuristic optimization algorithms", Structures, 25, pp. 335-346, 2020.

Kennedy, J., and Eberhart, R., "Particle swarm optimization", Proceedings of ICNN'95 - International Conference on Neural Networks, Perth, WA, Australia, 4, pp. 1942-1948, 1995.

Kirkpatrick, S., Gelatt, C. D., Vecchi, M.P., 1983. Optimization by Simulated Annealing. Science, 220, 671-680.

Madhu, A., Sreekumar, A., 2014. Wireless Sensor Network Security in Military Application using Unmanned Vehicle. International Journal of Electronics and Communication Engineering. 51-58.

Mehra, P.S., Doja, M. N., Alam, B., 2020. Fuzzy Based Enhanced Cluster Head Selection (FBECS) for WSN. Journal of King Saud University - Science. 32, 390-401.

Metropolis, N., Rosenbluth, A.W., Rosenbluth, M.N., Teller, A., Teller, E., 1953. Equation of State Calculations by Fast Computing Machines. J. Chem. Phys. 21, 1087-1092.

Mostafaie, T., Kyihabani, F. M., Navimipour, N. J., "A systematic study on meta-heuristic approaches for solving the graph coloring problem", Computers \& Operations Research, 120, 2020.

Radhika, S., Pangarajan, P., 2019. On Improving the Lifespan of Wireless Sensor Networks with Fuzzy Based Clustering and Machine Learning Based Data Reduction. Applied Soft Computing Journal. 83, 1-9.

Rajput, A., Kumaravelu, V.B., 2019. Scalable and Sustainable Wireless Sensor Networks for Agricultural Application of Internet of Things Using Fuzzyc-Means Algorithm. Sustainable Computing: Informatics and Systems. 22, 62-74.

Ramluckun, N., Bassoo, V., 2020. Energy-Efficient Chain-Cluster Based Intelligent Routing Technique for Wireless Sensor Networks. Applied Computing and Informatics.

Rashedi, E., Nezamabadi, H., Saryazdi, S., “GSA: A Gravitational Search Algorithm”, Information Sciences, 179, 2232-2248, 2009.

Shieh, H.L., Kuo, C.C., Chiang, C.M., 2011.Modified Particle Swarm Optimization Algorithm with Simulated Annealing Behavior and Its Numerical Verification. Applied Mathematics and Computation, 218, 4365-4383.

Sivakumar, P., Radhika, M.,2018. Performance Analysis of LEACH-GA over LEACH and LEACH-C in WSN. Procedia Computer Science, 125, 248-256.

Sodeifian, G., Sajadian, S.A., Ardestani, N.S., 2017. Experimental Optimization and Mathematical Modeling of The Supercritical Fluid Extraction of Essential Oil from Eryngium Billardieri: Application of simulated annealing (SA) algorithm. The Journal of Supercritical Fluids, 127, 146-157.

Thangaramya,K., Kulothungan, K., Logambigai,R., Selvi, M., Ganapathy, S. and Kannanc, A., "Energy aware cluster and neurofuzzy based routing algorithm for wireless sensor networks in IoT," Computer Networks, pp. 211-223, 2019.

Özkaraca 0, Keçebaş A, "Performance analysis and optimization for maximum exergy efficiency of a geothermal power plant using gravitational search algorithm", Energy Conversion and Management, 185, pp. 155-168, 2019.

Özkaraca Osman, Keçebaş Ali, Demircan Cihan, 2018. Comparative thermodynamic evaluation of a geothermal power plant by using the advanced exergy and artificial bee colony methods. ENERGY, 156, pp. 169-180, 2018.

Özkaraca Osman, 2018. A comparative evaluation of Gravitational Search Algorithm (GSA) against Artificial Bee Colony (ABC) for thermodynamic performance of a geothermal power plant. Energy, 1665, pp. 1061-1077, 2018.

Özkaraca Osman, Keçebaş Pınar, Demircan Cihan, Keçebaş Ali, 2017. Thermodynamic Optimization of a Geothermal- Based Organic Rankine Cycle System Using an Artificial Bee Colony Algorithm. Energies, 10(11), 2017.

Uysal, M., Özcan, U., 2019. Süpermarket Yerleşim Problemi İçin Tavlama Benzetimi Algoritması Yaklaşımı. Karadeniz Fen Bilimleri Dergisi, 9(1), 58-69.

Yadav, A., Kumar, S., Vijendara, S., 2018. Network Life Time Analysis of WSNs Using Particle Swarm Optimization. Procedia Computer Science. 132, 805-815

Yang, B., Wang, J., Zhang, X., Tu, T., Yao, W., Shu, S., Zeng, F., Sun, L., "Comprehensive overview of meta-heuristic algorithm applications on PV cell parameter identification", Energy Conversion and Management, 208, 2020.

Yang, X S., Chien, S F., Ting, T O., "Bio-Inspired Computation and Optimization: An Overview", in Bio-Inspired Computation in Telecommunications, pp. 1-21, 2015.

Zhang, W., Maleki, A., Rosen, M.A., Liu, J., 2018. Optimization with a Simulated Annealing Algorithm of a Hybrid System for Renewable Energy Including Battery and Hydrogen Storage. Energy, 163, 191-207. 